\title{
Article \\ Asymmetric Supercapacitors: Optical and Thermal Effects When Active Carbon Electrodes Are Embedded with Nano-Scale Semiconductor Dots
}

\author{
Haim Grebel (D)
}

Citation: Grebel, H. Asymmetric Supercapacitors: Optical and Thermal Effects When Active Carbon Electrodes Are Embedded with Nano-Scale Semiconductor Dots. C 2021, 7, 7. https://doi.org/10.3390/ c7010007

Received: 21 December 2020 Accepted: 13 January 2021 Published: 15 January 2021

Publisher's Note: MDPI stays neutral with regard to jurisdictional clai$\mathrm{ms}$ in published maps and institutional affiliations.

Copyright: (C) 2021 by the author. Licensee MDPI, Basel, Switzerland. This article is an open access article distributed under the terms and conditions of the Creative Commons Attribution (CC BY) license (https:// creativecommons.org/licenses/by/ $4.0 /)$.
The Center for Energy Efficiency, Resilience and Innovation (CEERI), The Electronic Imaging Center (EIC), The New Jersey Institute of Technology (NJIT), Newark, NJ 07102, USA; grebel@njit.edu

\begin{abstract}
Optical and thermal effects in asymmetric supercapacitors, whose active-carbon (AC) electrodes were embedded with nano-Si (n-Si) quantum dots (QD), are reported. We describe two structures: (1) p-n-like, obtained by using a polyethylimine (PEI) binder for the " $n$ " electrode and a polyvinylpyrrolidone (PVP) binder for the " $\mathrm{p}$ " electrode; (2) a single component binderpoly(methyl methacrylate) (PMMA). In general, AC appears black to the naked eye and one may assume that it indiscriminately absorbs all light spectra. However, on top of a flat lossy spectrum, AC (from two manufacturers) exhibited two distinct absorption bands: one in the blue ( 400 nm) and the other one in the near IR $(\sim 840 \mathrm{~nm})$. The n-Si material accentuated the absorption in the blue and bleached the IR absorption. Both bands contributed to capacitance increase: (a) when using aqueous solution and a PMMA binder, the optical-related increased capacitance was $20 \%$ for low n-Si concentration and more than $100 \%$ for a high-concentration dose; (b) when using ion liquid (IL) electrolyte, the large, thermal capacitance increase (of ca. $40 \%$ ) was comparable to the optical effect (of ca. $42 \%$ ) and hence was assigned as an optically induced thermal effect. The experimental data point to an optically induced capacitance increase even in the absence of the n-Si dots. Overall, the experimental data suggest intriguing possibilities for optically controlled supercapacitors.
\end{abstract}

Keywords: asymmetric supercapacitors; polymeric-doped supercapacitor electrodes; nano-semiconductor dots embedded in active carbon electrodes; supercapacitors: optical effects; supercapacitors: thermal effects

\section{Introduction}

Supercapacitors, S-C [1-3]-capacitors that take advantage of the capacitance at the interface between an electrode and an electrolyte-have been found in a large range of energy applications-least of all, optical modulators [4], and as buffering elements to subdue demand fluctuations in digital power networks $[5,6]$. A subclass of these is asymmetric S-C - capacitors made with two types of electrodes [7-9]. Asymmetric S-C are mostly fabricated as pseudo-supercapacitors - $\mathrm{S}-\mathrm{C}$ whose capacitance is associated with a chemical reaction at the electrolyte/electrode interface. Pseudo-supercapacitors are aimed at increasing the operation potential range [10-14] via electrochemical means. To these, one ought to add dye-sensitized solar cells [15,16], a special class of optically powered electrochemical energy sources with two distinct electrodes and an electrolyte that mediates the reacting ion species. Here, we describe carbon-based, optically controlled asymmetric S-C that do not exhibit a chemical reaction at their electrolyte/electrode interfaces; namely, we focus on basic, electrochemical double-layer (EDL) supercapacitors. In the past, nano particles were incorporated within active-carbon electrodes, yet meant for only electronic purposes [17-19]. Our intent is to gain a basic understanding of the optical and related thermal effects when incorporating $n$-Si dots in active carbon $(\mathrm{AC})$ based electrodes. We describe two S-C types, which are both embedded with n-Si dots: polymeric-doped AC electrodes 
via polyvinylpyrrolidone (PVP) and polyethylimine (PEI) binders, and non-doped AC electrodes with a poly(methyl methacrylate) (PMMA) binder.

\section{Materials and Methods}

The basic optoelectronic cell is composed of two transparent electrodes, either indium tin oxide (ITO, sheet resistance Rsqr $=20 \mathrm{Ohms}$ ) or fluorinated doped tin oxide (FTO, sheet resistance Rsqr $=30 \mathrm{Ohm}$ ) films on glass substrates. The electrodes were facing each other to form a parallel plate capacitor. The electrodes were coated with active-carbon (AC) film (either produced by American Hardwood, AH, or by General Carbon Company, GCC). In the case of p-n cells, the AC was incorporated in binders similarly to functionalize carbon nanotubes [20-25]. While the AC is not a semiconductor material, nevertheless, it was hypothesized that the small AC domains would make it susceptible to polymeric doping.

PVP and PEI Binders, p-n-like Cells: In the case of a p-n-like cell, the AC (various concentrations in the range $100-200 \mathrm{mg} / \mathrm{mL}$ ) in methanol was dispersed using a sonicator with a horn antenna. The n-Si dots, of size less than 100 nanometers and at various concentrations in the range of $1-10 \mathrm{mg} / \mathrm{mL}$, were mixed in mostly the PVP "p-type" material. The concentration range of the PVP was $20-40 \mathrm{mg} / \mathrm{mL}$ but larger than $10 \%$ by weight. Two molecular weights have been considered for the polymers: low m.w of $25 \mathrm{kD}$ and high m.w of $630 \mathrm{kD}$. Two molecular weights were also considered for PEI: low m.w of $25 \mathrm{kD}$ and $50 \%$ water diluted $600 \mathrm{kD}$. High m.w polymers were used previously [24] with CNT and they were thought to have better AC "doping" than the low m.w. polymers. However, preliminary results with high m.w polymers exhibited large equivalent series resistance (ESR) and relatively small capacitance values. Therefore, we focus here on low m.w. polymer binders. The irradiation on n-Si embedded PEI resulted in pseudo-capacitor behavior (Figure 1d) and, hence, n-Si were incorporated into either the PVP or the PMMA. The slurries were drop-casted on the transparent electrodes and were dried out at $90{ }^{\circ} \mathrm{C}$ for $30 \mathrm{~min}$. The entire structure was held by a strong clip, leaving an exposed surface for light illumination. The illuminated (exposed) area was smaller than the entire area of the S-C. Typically, the area for p-n samples was $1 \times 1 \mathrm{~cm}^{2}$ whereas the AC/PMMA samples were larger, ca. $2 \times 2.5 \mathrm{~cm}^{2}$. The capacitance change of a given sample was assessed as a relative value: under light irradiation and without it. Sample temperature increased as a result of the optical absorption. A baseline for capacitance change due to pure thermal effect was established.

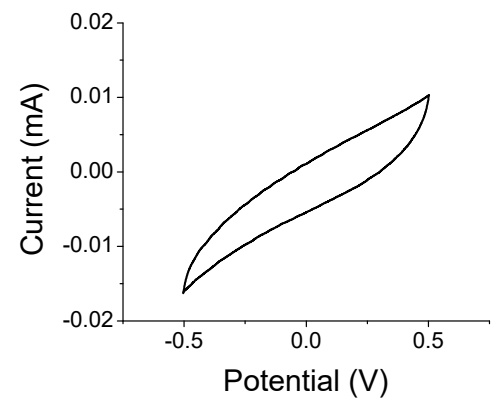

(a)

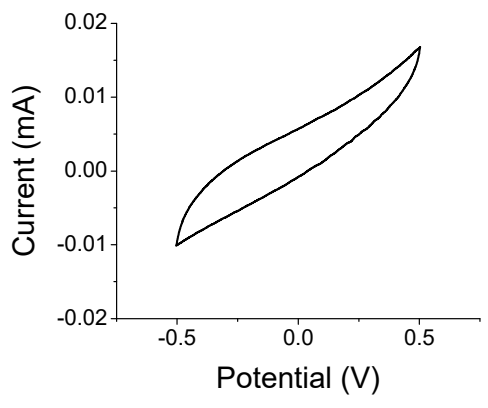

(b)

Figure 1. Cont. 


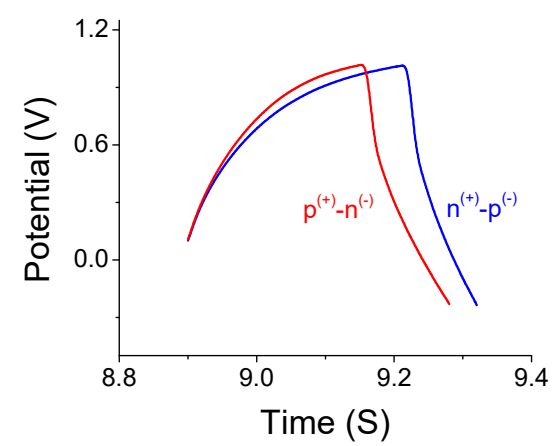

(c)

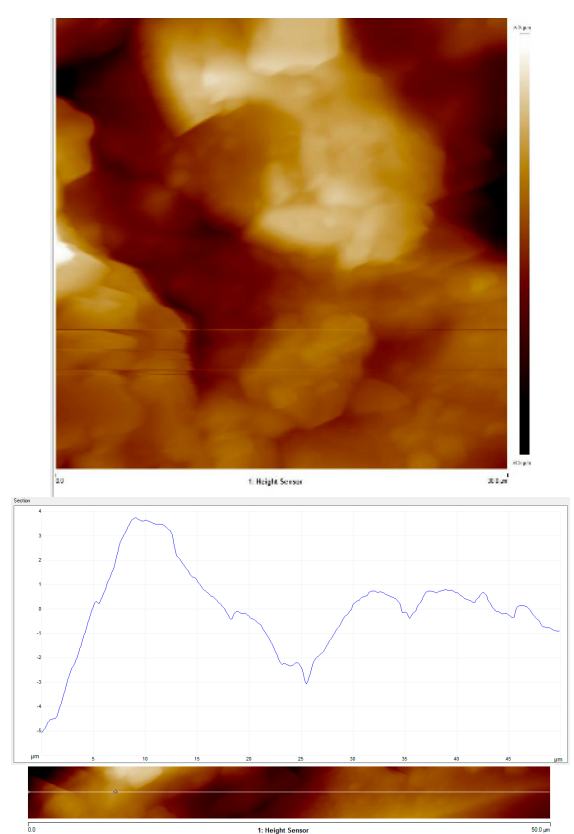

(e)

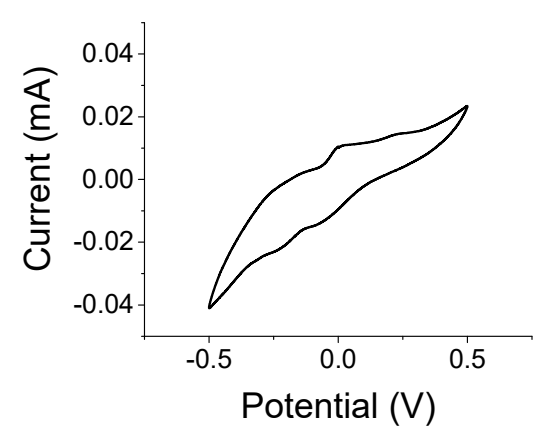

(d)

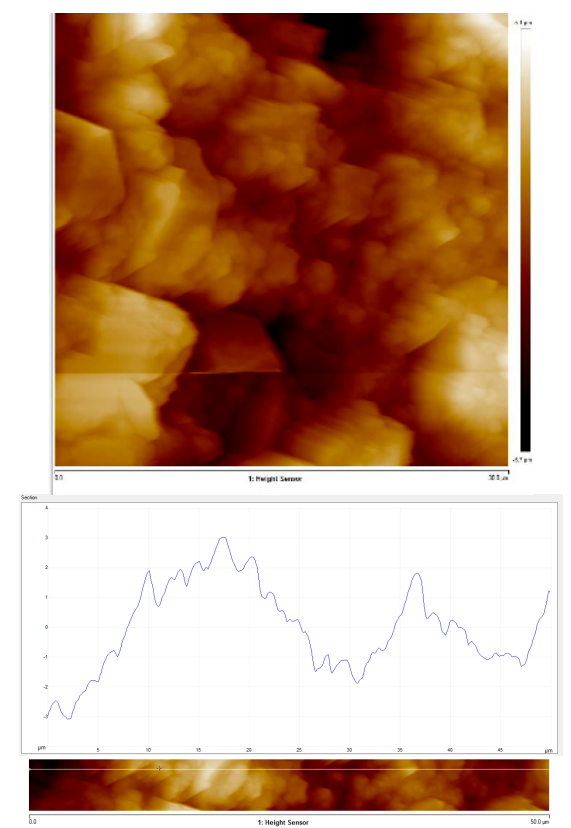

(f)

Figure 1. (a,b) Cyclic voltammetry $(\mathrm{CV})$ curves at scan rate of $0.1 \mathrm{~V} / \mathrm{s}$ for AC/PVP-AC/PEI low m.w. cell with ion liquid (IL) electrolyte and Al current collectors. (a) When the positive lead of the potentiostat was connected to the AC/PVP side and the negative lead was connected to the $\mathrm{AC} / \mathrm{PEI}$ side. (b) When the leads have been switched: the positive lead of the potentiostat was connected to the AC/PEI side and the negative lead was connected to the AC/PVP side. (c) ChargeDischarge (CD) curves: red curve is when the positive lead is connected to AC/PVP; blue curve is when the positive lead is connected to AC/PEI. (d) Incorporating n-Si in both electrode material and, more specifically, in $\mathrm{AC} / \mathrm{PEI}$ resulted in a pseudo-capacitor behavior when using an aqueous electrolyte. (e,f) $30 \times 30$ micron $^{2}$ AFM scanned images of AC/PVP/n-Si and AC/PEI electrodes, respectively, on FTO. The color height bar extends from -6 (dark) to 5 (bright white) microns and their respective linear scans. The respective linear scan along 50 microns is shown below each image. The $y$-scale (height) is from -4 to +4 microns.

Film surface was analyzed by Atomic Force Microscope (AFM) as shown in Figure 1e,f. Film thickness was assessed by measuring the substrate weight difference upon film deposition, $\Delta \mathrm{W}$, and taking into account the fraction weight, $\mathrm{f}_{\mathrm{i}}$, of each film component: $\mathrm{d}_{\text {eff }}$, the effective

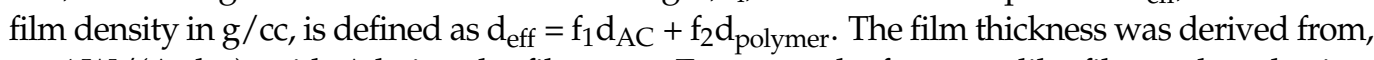
$\mathrm{t}=\Delta \mathrm{W} /\left(\mathrm{A} \cdot \mathrm{d}_{\mathrm{eff}}\right)$, with $\mathrm{A}$ being the film area. For example, for a $\mathrm{p}-\mathrm{n}$-like film and neglecting the small weight of $n-S i, f_{2} / f_{1}=0.15$. The density of $A C$ was measured as $0.35 \mathrm{~g} / \mathrm{cc}$ and the density of PVP is $1.2 \mathrm{~g} / \mathrm{cc}$. Therefore, $\mathrm{d}_{\text {eff }}=0.85 \times 0.35+0.15 \times 1.2=0.48 \mathrm{~g} / \mathrm{cc}$. The weight difference was $3 \mathrm{mg}$. Thus, $\mathrm{t}=3 /\left(480 \times 1^{2}\right) \sim 63$ microns. 
PMMA Binder: The adhesion of PEI and PVP to the conductive glass with IL was good; the films sometimes peeled off when aqueous cells were taken apart. PMMM binder worked better under these circumstances with both IL and Na2SO4 electrolytes. The n-Si were incorporated within the electrode facing the light source. Typically, a $200 \mathrm{mg} / \mathrm{mL}$ AC produced by GCC with a $20 \mathrm{mg} / \mathrm{mL}$ PMMA binder on FTO or ITO was used. The $2 \mathrm{mg} / \mathrm{mL}$-Si was added to the slurry with the other components in Anisole, sonicated with a horn antenna and drop-casted on the conductive glass substrate. The film was dried out in an oven at $90^{\circ} \mathrm{C}$ for $30 \mathrm{~min}$. With a PMMA binder, $\mathrm{f}_{2} / \mathrm{f}_{1}=0.1, \mathrm{~A} \sim 5 \mathrm{~cm}^{2}, \Delta \mathrm{W}=34 \mathrm{mg} ; \mathrm{t} \sim 156$ microns.

Electrolytes: $98 \%$ ionic liquid (IL, Alfa-Aesar) [26-28] and $1 \mathrm{M} \mathrm{Na}_{2} \mathrm{SO}_{4}$ were used as electrolytes. For IL, we used 1-n-Butyl-3-methyl-imidazolium hexafluro-phosphate. The ionic liquid was soaking 0.1-mm-thick lens tissues (Bausch \& Lomb) used as separators. Using a hydrophilic nano-filtration polyamide filter (TS80, Sterlitech) proved to be too resistive for the as-is IL; both the tissue and the membrane worked well with the $1 \mathrm{M}$ of $\mathrm{Na}_{2} \mathrm{SO}_{4}$ electrolyte.

Electrochemical Measurements: Measurements were carried out with a Potentiostat/Galvanostat (Metrohm). The samples were irradiated with a 75-W incandescent light bulb situated $30 \mathrm{~cm}$ above the samples. The light intensity of the entire radiation spectra (from the visible to the IR) was measured with a bolometer and was assessed as $30 \mathrm{~mW} / \mathrm{cm}^{2}$. A calibrated homemade hot plate, which was interfaced with a thermocouple, was used for the thermal experiments. A second thermocouple assessed the temperature precisely at the sample surface.

Electrical Measurements: Current-voltage plots (I-V curves) on dry films were obtained with a sensitive, $100 \mathrm{fA}$, computer-controlled dedicated system (Keithley).

Optical Transmission Measurements: A computer-controlled monochromator (SPEX), which was interfaced with a white light source, a chopper and a Si detector, was used to assess the optical transmission of each film on a glass substrate. The transmission value was assessed as the signal obtained with the film on the glass slide divided by the signal obtained with only the glass slide.

\section{Results and Discussion}

\subsection{Film Characterizations}

Asymmetric Cells: The asymmetry of the capacitive element is demonstrated in Figure 1a,b. Shown are cyclic voltammetry $(\mathrm{CV})$ curves at a scan rate of $0.5 \mathrm{~V} / \mathrm{s}$ for a cell made with concentrations of AC, PVP, PEI, as follows: $100 \mathrm{mg} / \mathrm{mL}, 20 \mathrm{mg} / \mathrm{mL}$ and $20 \mathrm{mg} / \mathrm{mL}$ with the lower m.w. polymers. The " $\mathrm{p}$ "-like electrode was made of AC/PVP on $\mathrm{Al}$ and the " $\mathrm{n}$ "-like electrode was made of AC/PEI also on Al. The AC was made by $\mathrm{AH}$ and the electrolyte was IL soaking a tissue separator. The curves were mirror images of each other when the positive and negative leads were switched; namely, the effect may not be attributed to Schottky barrier at the contacts. Figure 1a was obtained when the positive lead of the potentiostat was connect to the AC/PVP electrode (denoted as $\mathrm{p}^{(+)}$) and the negative lead of the potentiostat was connected to the AC/PEI side (denoted as $\mathrm{n}^{(-)}$). Figure $1 b$ was obtained when lead connections were switched-namely, $n^{(+)}-\mathrm{p}^{(-)}$.

Charge-discharge (CD) curves (Figure 1c) conveyed the same message: the rise time is shorter and the discharge time is longer for $\mathrm{p}^{(+)}-\mathrm{n}^{(-)}$, whereas the reverse is true when the lead connections are switched. Granted that the S-C is less than perfect; it was of the order of tens of micro-F for this $0.5 \mathrm{~cm}^{2}$ capacitor. Figure $1 \mathrm{~d}$ exhibits a pseudo-capacitive nature when the $\mathrm{n}-\mathrm{Si}$ is incorporated in the AC/PEI electrode.

The film surface is shown in Figure 1e,f. The AFM scan in a cell of $30 \times 30$ microns $^{2}$ exhibited a grain width of ca. 15 microns and height in the range of \pm 4 microns (limited by the machine specifications). Overall, it seems that the grain size here is of the order of 15 microns.

Optical Transmission and I-V Curves: The optical transmission through the various material components is shown in Figure 2a. Since the films' thickness varied and we are only interested in the spectral shape of the curves, each transmission curve was normal- 
ized to its peak transmission. The glass slide signal was referenced to the transmission through air; all other curves were referenced to the signal of their substrate-a glass slide. The transmission of a glass slide is fairly constant throughout the spectral range between 400 and $900 \mathrm{~nm}$. The transmission of the ITO and FTO on glass is flat throughout the visible with an overall transmission coefficient of 0.8; PMMA has also a flat transmission in the visible with a transmission coefficient of 0.9 (not shown).

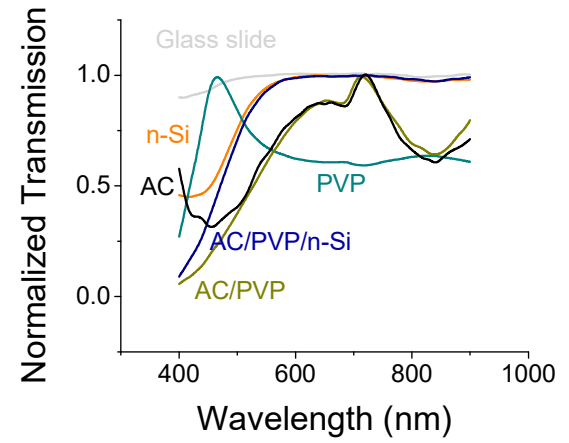

(a)

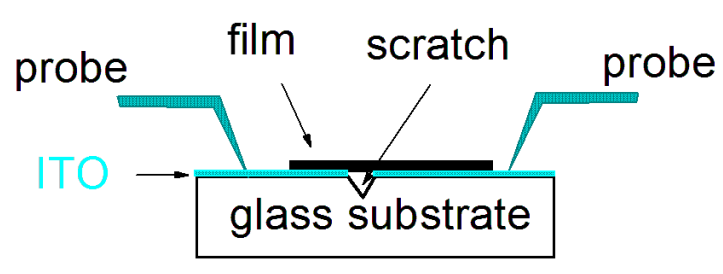

(c)

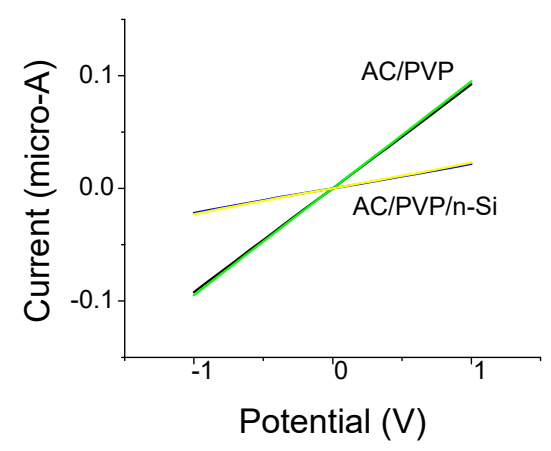

(b)

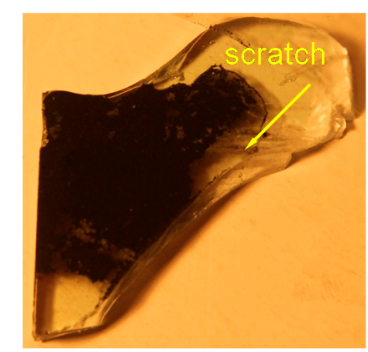

(d)

Figure 2. (a) Normalized optical transmission through the various film components used in the experiments. The peak transmission was set to 1 for each curve in order to accentuate the spectral response. The transmission of the glass slide was referenced to air. All other transmission values were referenced to the transmitted signal through the glass slide. (b) I-V curves for AC/PVP and AC/PVP/n-Si under illumination of $30 \mathrm{~mW} / \mathrm{cm}^{2}$ light bulb and in the dark (room lighting). The inset shows the measurement arrangement. The effect is small but nonetheless measurable. (c) The setup for measuring conductivity with and without illumination (the light irradiates the film from above). (d) A picture of AC/PVP film bridging a scratched ITO glass substrate.

The yellowish n-Si powder absorbs heavily in the blue green spectral range, as is typical for these nano-scale dots. The indirect bandgap of Si at 1.1 microns turns into a direct bandgap and its absorption is blue-shifted when the dot size becomes smaller. The AC film exhibited two distinct absorption bands regardless of maker (the one depicted in the picture has been produced by American Hardwood (AH)). One absorption band is in the blue, centered at $460 \mathrm{~nm}$, and the other is in the near IR, centered at $840 \mathrm{~nm}$. PVP absorbs in the deep blue and portrays flat absorption for wavelengths between 500 and $900 \mathrm{~nm}$. The absorption of AC/PVP followed that of only AC. Most notable is the transmission of PVP $/ \mathrm{n}-\mathrm{Si}$ (not shown) and AC/PVP $/ \mathrm{n}-\mathrm{Si}$. The absorption peak at $840 \mathrm{~nm}$ disappeared, leaving only an absorption peak in the blue. Additionally noted is the blue shift for the $460 \mathrm{~nm}$ absorption line to below $400 \mathrm{~nm}$ with a combined effect that is larger than for either components. The behavior at $840 \mathrm{~nm}$ may be explained if the absorption line is attributed to impurity doping or surface states. Electrons were transferred from the AC (donors) to the n-Si (acceptors) and the transition was bleached. The behavior near $400 \mathrm{~nm}$ is more complex and could involve dipole coupling between the AC and n-Si species.

In Figure $2 b$, we show the I-V curve of illuminated and non-illuminated dry films made of AC/PVP and AC/PVP/n-Si on ITO. The setup for the conductivity measurements is shown in Figure $2 \mathrm{c}$ and a picture of a scratched sample is shown in Figure 2d. As shown, 
a 1-mm scratch was made in the ITO layer, preventing electrical conduction across it. The deposited film was bridging the gap and enabled conduction (Figure $2 \mathrm{c}, \mathrm{d}$ ). There are two takeaways from the experiments: (1) the ITO/AC films exhibited Ohmic contacts; and (2) the film conductivity has increased under white light illumination. The films thicknesses and widths were not the same, which explains the difference in the curves' slopes. Nevertheless, we can assess the relative conductivity $(\sigma=\mathrm{I} / \mathrm{V})$ change under illumination: it was $\left(\sigma_{\text {illuminated }}-\sigma_{\text {dark }}\right) / \sigma_{\text {dark }}=5.5 \times 10^{-2}=5.5 \%$ for the AC $/ \mathrm{PVP} / \mathrm{n}-\mathrm{Si}$ and $3 \times 10^{-2}=3 \%$ for the AC/PVP film. As expected, the $n-S i$ has improved the film conductivity under light even though its concentration was of the order of a few percent compared with a typical $20 \%$ conductive additives in commercial S-C material [28].

\subsection{Supercapacitors under Light ON and Light OFF Conditions}

In the remainder of this paper, we will examine the optical and related thermal effects in these films. In Figure 3, we show CV and CD curves for a p-n cell- $-p(A C / P V P / n-S i)-$ $\mathrm{n}(\mathrm{AC} / \mathrm{PEI}$ - - under light $\mathrm{ON}$ and light OFF. The CV curves are asymmetric when light is OFF (room light) and ON. The sample was deposited on ITO with a lens tissue separator soaked with IL. Capacitance increase can be observed in Figure 3a. The relative capacitance increase should be normalized by the respective differences between the illuminated and non-illuminated areas: $\left[(\mathrm{C} / \mathrm{A})_{\text {illum }}-(\mathrm{C} / \mathrm{A})_{\text {dark }}\right] /(\mathrm{C} / \mathrm{A})_{\text {dark }}=0.42$ or a $42 \%$ increase under illumination. Upon illumination, one may observe a tilt of the plot axis towards larger current values. Such tilt may be attributed to a larger film conductivity and a lower ESR. The latter is corroborated by $\mathrm{CD}$ data (Figure $3 \mathrm{~b}$ ). Capacitance here is calculated for the decay branch as $\mathrm{C}_{\text {eff }} \sim\left(\mathrm{I}_{0} /\left(\mathrm{V}_{0} / \tau\right)\right.$, which replaces the usual linear expression, $\mathrm{C}=\mathrm{I}_{0} /(\mathrm{dV} / \mathrm{dt})$. Here, $I_{0}$ is the (constant) discharge current, $1 / \tau$ is a single decay rate that approximates the discharged branch, $V_{0}$ is the voltage difference $\left(V_{0}=1 \mathrm{~V}\right.$ in our case) and $C_{\text {eff }}$, the effective capacitance across the various film regions as it is gradually discharged. The relative capacitance change under illumination is $\sim 37 \%$. Overall, the ESR is quite large and may be attributed to the large impedance of the current collector (ITO; Rsqr $=20$ Ohms compared to $2.7 \mathrm{mOhms}$ of $\mathrm{Al}$ ), use of IL and non-optimized binder to $\mathrm{AC}$ ratio.

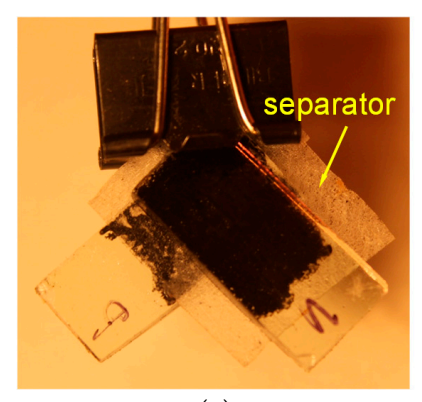

(a)

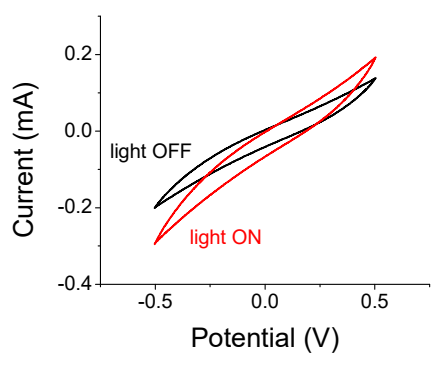

(b)

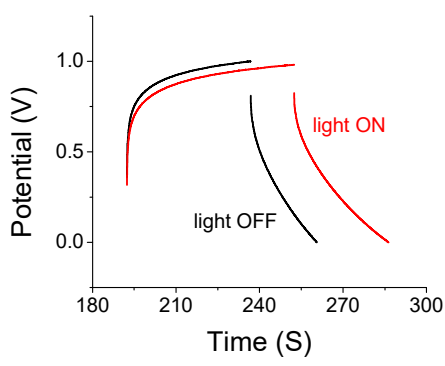

(c)

Figure 3. (a) A picture of a $\mathrm{p}(\mathrm{AC} / \mathrm{PVP} / \mathrm{n}-\mathrm{Si})-\mathrm{n}(\mathrm{AC} / \mathrm{PEI})$ cell with tissue-soaked IL electrolyte on FTO glass. The cross-section of the p-and the n-electrodes is $1 \mathrm{~cm}^{2}$. (b) $\mathrm{CV}$ at a scan rate of $0.5 \mathrm{~V} / \mathrm{s}$ under illuminated and non-illuminated conditions. (c) Corresponding CD curves. A small ESR decrease is noted under illumination. Note the rotated curve in (a) and the increase in both the charge and discharge time constants in (b) under the illumination with white light. 


\subsection{Thermal Considerations during Light ON and Light OFF Conditions}

\subsubsection{PMMA Binder with Aqueous Solution}

Let us start with the simpler system using a single electrode binder (PMMA), where the electrode facing the light source is embedded with n-Si dots. In Figure $4 a$,b, we present two $\mathrm{CV}$ plots: Figure 4a has been obtained when heating the sample from 23 to $35^{\circ} \mathrm{C}$, at the rate of $0.1{ }^{\circ} \mathrm{C} / \mathrm{s}$, while collecting the $\mathrm{CV}$ data continuously. The light was OFF and the curve served as a reference. The AC manufacture was GCC and the electrolyte was $1 \mathrm{M} \mathrm{Na}_{2} \mathrm{SO}_{4}$. The loading of the $\mathrm{n}-\mathrm{Si}$ was $2 \mathrm{mg} / \mathrm{mL}$. Note the rotation of the curve as the sample heats up; its waist at zero potential has changed only slightly. The relative change from the first scan to the last was $<2 \%$. Figure $4 \mathrm{~b}$ exhibits two CV curves for light OFF and light ON. Upon illumination, the temperature at the sample surface has elevated to $27^{\circ} \mathrm{C}$. The relative capacitance change for the ON/OFF case was 20\% (including the fact that the exposed illuminated area is smaller than the area of the entire S-C), clearly larger than the thermal reference. While the curve has rotated, its waist has increased too. Finally, CV curves were obtained with AC electrodes and only PMMA as a binder (namely, without n-Si). As seen from Figure $4 c$, there is a small optical effect when considering the smaller illuminated area of the S-C, while the temperature at the sample surface has reached $30{ }^{\circ} \mathrm{C}$ under optical illumination. Heating of the AC electrode even without n-Si is attributed to an overall AC scattering/absorption. Thus, while the optical-related heating is substantial, the increase in local polarization is small.

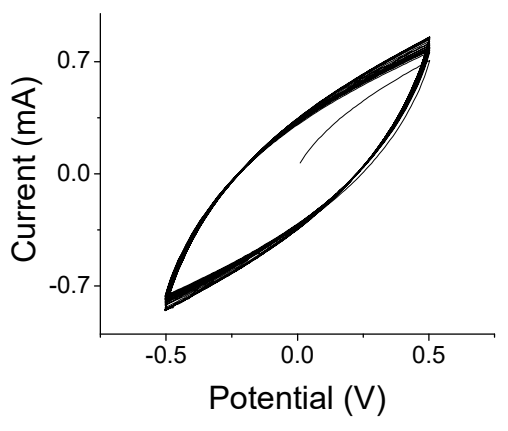

(a)

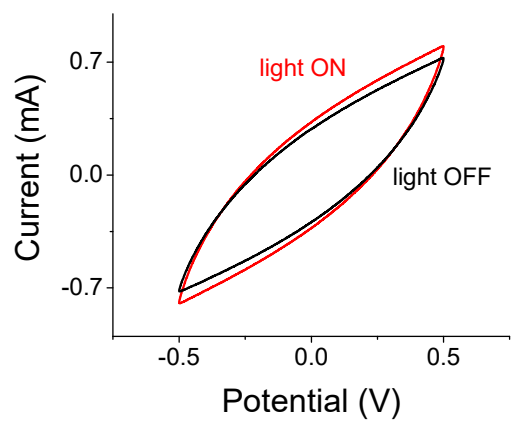

(b)

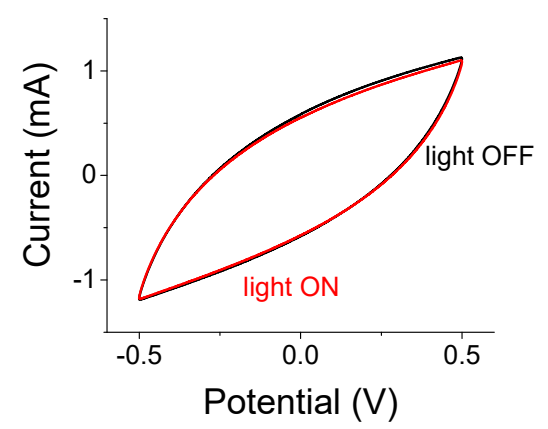

(c)

Figure 4. $\mathrm{CV}$ curves for $\mathrm{AC}$ in PMMA binder with $1 \mathrm{M} \mathrm{Na}_{2} \mathrm{SO}_{4}$ electrolyte soaking a TS80 membrane and n-Si loading of $2 \mathrm{mg} / \mathrm{mL}$. Curves were obtained at a scan of $0.1 \mathrm{~V} / \mathrm{s}$. (a) Calibration curve when the sample was heated when light was OFF from 23 to $35^{\circ} \mathrm{C}$. Note the rotation of the curve as the sample heats up; its waist, however, at zero potential barely changed. (b) CV curves for light OFF (room lighting) and light ON. While the curve has rotated, its waist has increased too. (c) AC with PMMA binder yet without $\mathrm{n}$-Si has exhibited a small optical effect if we take into account the smaller area exposed to the light.

An easy calibration method may be made with the one S-C cell. In that case, one compares the effect of illumination for two cases: the case when the electrode containing n-Si 
dots is facing the light source and the case when the other electrode, the one without the dots, is facing the light source. This experiment is presented in Figure 5. Both electrodes were deposited on an ITO with Rsqr $=5 \mathrm{Ohms}$ (Huanyu). The electrolyte was $\mathrm{Na}_{2} \mathrm{SO}_{4}$ and the cell has reached $26{ }^{\circ} \mathrm{C}$ in both cases during illumination. The concentration of the n-Si dots was $10 \mathrm{mg} / \mathrm{mL}$, substantially larger than all other cases described before. Specifically, when the electrode without $\mathrm{n}-\mathrm{Si}$ was facing the light source, the relative OFF/ON change was ca. $11 \%$ ( $22 \%$ when considering the smaller light exposed area); it was $56 \%$ (112\% when considering the smaller light exposed area) for the electrode containing the n-Si dot and facing the light source. Based on Figures $4 \mathrm{c}$ and $5 \mathrm{a}$, one may postulate that there could be an optical effect even in the absence of n-Si dots due to absorption of AC in the blue.

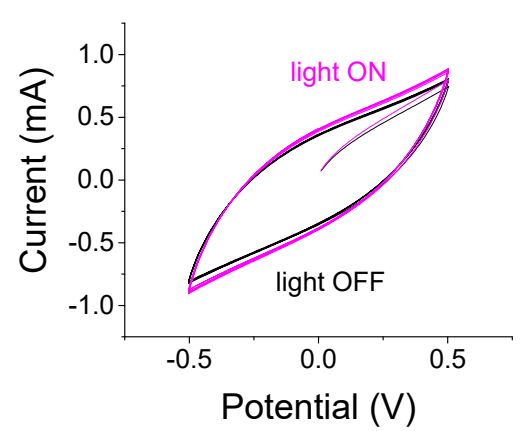

(a)

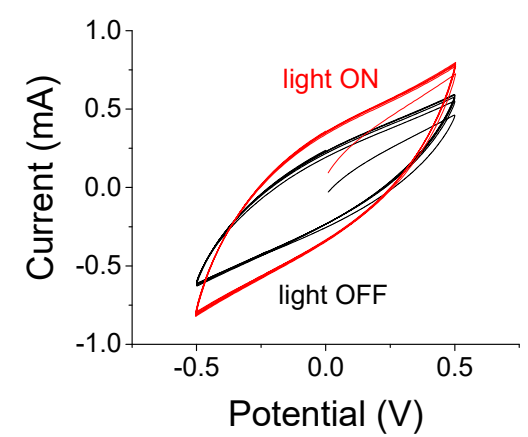

(b)

Figure 5. Measuring the cell capacitance when the electrode without the n-Si dot is facing the light source, (a), and when the electrode containing the dots is facing the light source. In both cases, the surface of the sample reached $26^{\circ} \mathrm{C}$. The $\mathrm{n}$-Si loading was $10 \mathrm{mg} / \mathrm{mL},(\mathbf{b})$.

\subsubsection{PMMA Binder with Ion Liquid Electrolyte}

In order to assess whether the capacitance increase is due to the resulting heating of the electrolyte through light absorption, we repeated the previous measurements and replaced the aqueous solution with an IL electrolyte. The AC electrode here was embedded with a higher $\mathrm{n}-\mathrm{Si}$ concentration $-10 \mathrm{mg} / \mathrm{mL}$. Figure 6a presents the capacitance increase upon heating from 23 to $45^{\circ} \mathrm{C}$ at a rate of $0.1^{\circ} \mathrm{C} / \mathrm{s}$. Here, too, the light was OFF and the heated sample served as reference. The $\mathrm{CV}$ data were continuously collected throughout the heating process. Figure $6 \mathrm{~b}$ shows the related $\mathrm{CV}$ curves upon light $\mathrm{ON}$ and light $\mathrm{OFF}$. A large capacitance increase is noted: the relative capacitance increased by $50 \%$ when the sample was heating up from $23{ }^{\circ} \mathrm{C}$ to $37^{\circ} \mathrm{C}$ (Figure 6a). Similarly, a ca. $50 \%$ capacitance increase and related temperature increase is noted based on Figure $6 \mathrm{~b}$. Thus, and unlike Figure 4, we cannot separate here the optical effect from the electrolyte-related, thermal effect. Similar conclusions could be drawn when a lower concentration of n-Si was used.

\subsection{3. p-n Binders with Ion Liquid Electrolyte}

CV were obtained for p-n-like cell ( $n-S i$ in AC/PVP and AC/PEI, respectively). The electrolyte was IL. In Figure 7a, we present a CV curve when heating the sample from $23{ }^{\circ} \mathrm{C}$ to $35^{\circ} \mathrm{C}$ while collecting the $\mathrm{CV}$ data continuously, all while the light source was OFF. The heating rate was $0.1{ }^{\circ} \mathrm{C} / \mathrm{sec}$. The relative change from the first scan to the last was ca. $40 \%$. Figure $7 \mathrm{~b}$ exhibits two CV curves for light OFF and light ON. Upon illumination, the temperature at the sample surface has elevated to $30^{\circ} \mathrm{C}$. The relative capacitance change for the ON/OFF case was 35\%. Using the calibration curve of Figure $7 \mathrm{a}$, the thermal effect between 23 and $30{ }^{\circ} \mathrm{C}$ may account for only $23 \%$ of the capacitance increase while the remaining $13 \%$ could be attributed to the optical effect. This last value is similar to the value obtained for the aqueous system. Nonetheless, since the p-n is a more complex system than the one involving PMMA, and recognizing that the conductivity of PVP changes upon light illumination (Figure $2 b$ ), more data are needed to affirmatively determine the portion of the optical effect with IL electrolytes. We point to recent studies that showed that the 
thermal sensitivity of IL could be substantially decreased by using a proper mixture [27] and could be used here to accentuate the optical effect; such a study is beyond the scope of the current manuscript.

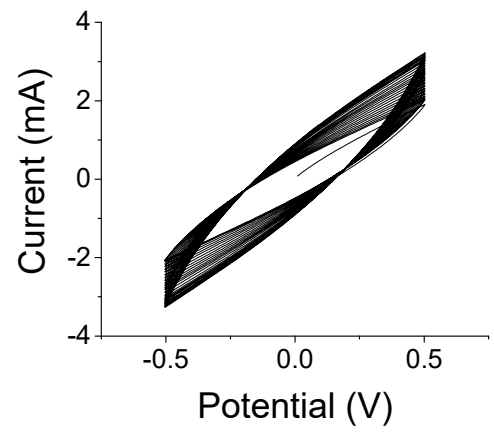

(a)

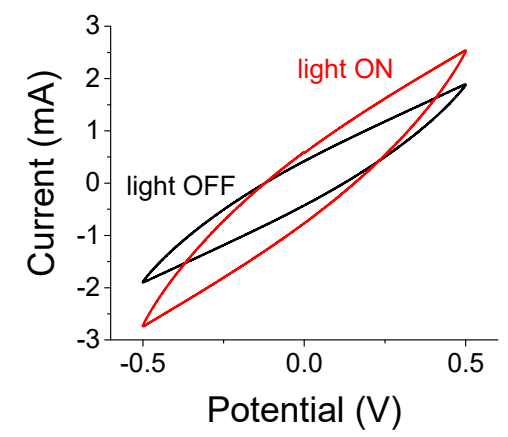

(b)

Figure 6. $\mathrm{CV}$ curves for $\mathrm{AC}$ embedded with high concentration of $\mathrm{n}-\mathrm{Si}(10 \mathrm{mg} / \mathrm{mL})$ with a PMMA binder. The IL electrolyte was soaking a lens tissue. Curves were obtained at a scan of $0.1 \mathrm{~V} / \mathrm{s}$. (a) Calibration curve when the sample was heated when light was OFF from 23 to $45^{\circ} \mathrm{C}$. Note the rotation of the curve as the sample heats up. (b) CV curves with light OFF (room lighting) and light $\mathrm{ON}$. The sample heated up from $23^{\circ} \mathrm{C}$ to $37^{\circ} \mathrm{C}$ upon illumination.

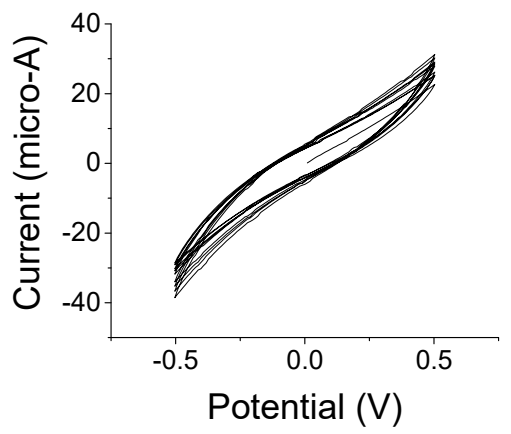

(a)

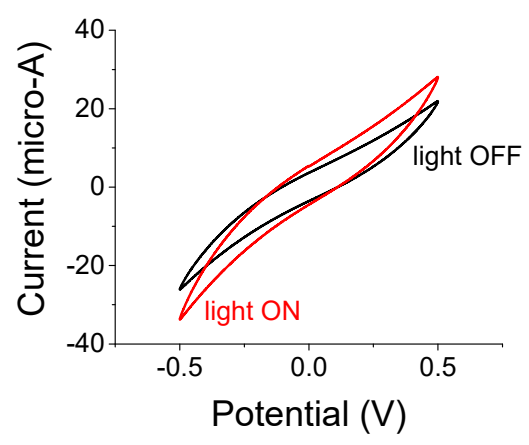

(b)

Figure 7. CV curves for p-n-like cell with IL electrolyte. Curves were obtained at a scan of $0.1 \mathrm{~V} / \mathrm{s}$. (a) Calibration curve when the sample was heated when light was OFF from 23 to $35^{\circ} \mathrm{C}$. (b) $\mathrm{CV}$ curves when the white light illumination was OFF and ON. Overall, the thermal effect from the IL dominated the capacitance increase.

\subsection{4. $\mathrm{p}-\mathrm{n}$ Binders with Aqueous Solution}

The thermal response of $\mathrm{p}$-n-like cells may be corroborated by using $\mathrm{Al}$ electrodes, $1 \mathrm{M}$ $\mathrm{Na}_{2} \mathrm{SO}_{4}$ electrolyte and eliminating the $\mathrm{n}$-Si QDs from the electrode composition. Figure 8 shows $C D$ curves for the $\mathrm{p}(\mathrm{AC} / \mathrm{PVP} / \mathrm{n}-\mathrm{Si})-\mathrm{n}(\mathrm{AC} / \mathrm{PEI})$ sample. The sample was heated by a 75-W lamp (although the Al current collector prevented any light penetration) and the temperature was recorded at the sample surface by using a thermocouple point probe. The AC was manufactured by GCC. The $<2 \%$ difference in the discharge time may be more to do with the instability of the binder in the aqueous electrolyte than with the heat. Therefore, we reiterate that aqueous solutions at the small temperature range studied have little thermal effect on the cell capacitance. 


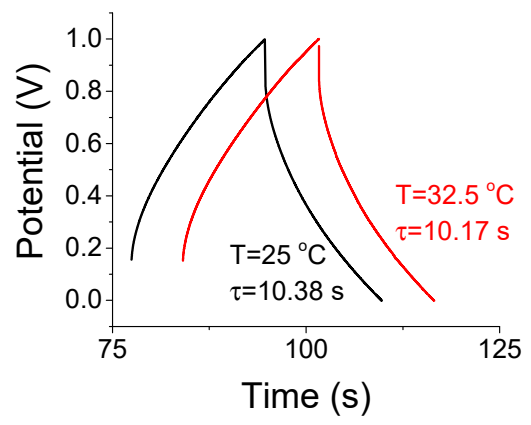

Figure 8. CD curves at two temperatures for $\mathrm{S}-\mathrm{C}, \mathrm{p}(\mathrm{AC} / \mathrm{PVP} / \mathrm{n}-\mathrm{Si})-\mathrm{n}(\mathrm{AC} / \mathrm{PEI})$ interfaced with $\mathrm{Al}$ electrodes and $\mathrm{Na}_{2} \mathrm{SO}_{4}$. The decay times for the discharge are shown in the figure. The slight change $(<2 \%)$ is attributed to imperfect contacts. No major capacitance change is noted when using the aqueous solution.

\subsection{The Effect of IR Absorption Band at $840 \mathrm{~nm}$}

As discussed earlier, the incorporation of n-Si dots bleached the absorption band at $840 \mathrm{~nm}$. Further corroboration may be obtained when measuring the capacitance while using a yellow optical filter. The filter transmits wavelengths larger than the cut-off wavelength of $550 \mathrm{~nm}$, thus eliminating the blue band from the white-light spectra. One has to factor in the reduced overall light intensity when the light source is interfaced with such a filter. The intensity of the light source interfaced with the filter was $70 \%$ of the total white light output (both visible and IR) as measured by use of a bolometer. Thus, if the intensity-related effects are linear, the capacitance increase due to the optical effect and/or thermal effect would be $70 \%$ of the effect without the filter.

Figure 9 a shows that a $\mathrm{p}(\mathrm{AC} / \mathrm{PVP} / \mathrm{n}-\mathrm{Si})-\mathrm{n}(\mathrm{AC} / \mathrm{PEI})$ on FTO with IL electrolyte, illuminated with a filter-interfaced white-light source, exhibited the same characteristics as non-illuminated S-C. On the other hand, a p(AC/PVP)-n(AC/PEI) on FTO (without n-Si) in Figure $9 \mathrm{~b}$ showed that the characteristics of light $\mathrm{ON}$ with and without the filter are the same; both were different from the light OFF situation. When using the filter, we eliminated the heating through blue light absorption but absorption was still present through the IR band.

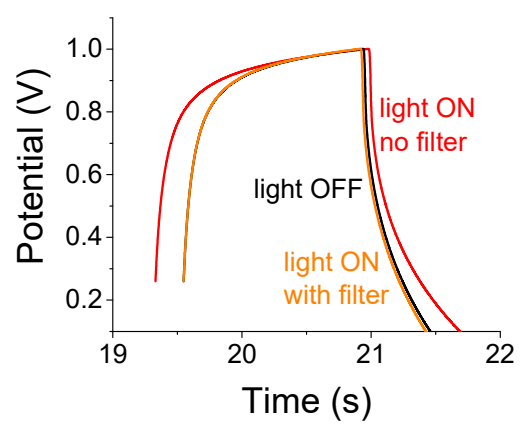

(a)

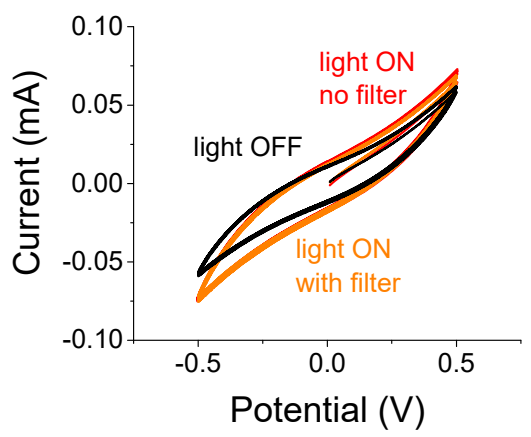

(b)

Figure 9. Assessing the effect of the IR absorption band with IL electrolyte: (a) for p-n-like S-C when $\mathrm{n}$-Si are embedded in the "p-like" electrode. Results for light OFF and light ON with the yellow filter are similar. (b) p-n only (no n-Si): results for light $\mathrm{ON}$ and light $\mathrm{ON}$ with the yellow filter are similar. The filter transmits wavelengths larger than the cut-off wavelength of $550 \mathrm{~nm}$.

All of the above may be summed up as follows: the IL was heated up through only the blue band absorption when the electrode contained n-Si; the n-Si eliminated the IR absorption band and the filter eliminated the blue absorption band. In the absence of n-Si, the sample was heated through both the blue and the IR bands; while the filter eliminated 
the absorption in the blue, the electrolyte was still heated through the absorption in the IR. In both cases, there was an increase in the relative cell capacitance.

\section{Conclusions}

Asymmetric S-C, embedded with n-Si QD, have shown a large capacitance increase. For aqueous cells, this was due to local polarizations even in the absence of n-Si dots. Cells interfaced with IL electrolyte exhibited a capacitance increase that was attributed to optically induced thermal effects in the electrolyte itself. Overall, such optoelectronic elements exhibit promise for novel, optically controlled supercapacitors.

Funding: This research received no external funding.

Institutional Review Board Statement: Not applicable.

Informed Consent Statement: Not applicable.

Data Availability Statement: Data available upon reasonable request.

Acknowledgments: To X. Zhang, NJIT, for AFM images.

Conflicts of Interest: The author declares no conflict of interest.

\section{References}

1. Simon, P.; Burke, A.F. Nanostructured Carbons: Double-Layer Capacitance and More. Electrochem. Soc. Interface 2008, 17, 38-43. [CrossRef]

2. Inagaki, M.; Konno, H.; Tanaike, O. Carbon materials for electrochemical capacitors. J. Power Sources 2010, 195, 7880-7903. [CrossRef]

3. Zhang, S.; Pan, N. Supercapacitors Performance Evaluation. Adv. Energy Mater. 2015, 5, 1401401. [CrossRef]

4. Polat, E.O.; Kocabas, C. Broadband Optical Modulators Based on Graphene Supercapacitors. Nano Lett. 2013, 13, 5851-5857. [CrossRef] [PubMed]

5. Miao, X.; Rojas-Cessa, R.; Mohamed, A.; Grebel, H. The Digital Power Networks: Energy Dissemination Through a Micro-Grid. In Proceedings of the 2018 IEEE International Conference on Internet of Things (iThings) and IEEE Green Computing and Communications (GreenCom) and IEEE Cyber, Physical and Social Computing (CPSCom) and IEEE Smart Data (SmartData), Halifax, NS, Canada, 30 July-3 August 2018.

6. Rojas-Cessa, R.; Grebel, H.; Jiang, Z.; Fukuda, C.; Pita, H.; Chowdhury, T.S.; Dong, Z.; Wan, Y. Integration of Alternative Energy Sources into Digital Micro-Grids. Environ. Prog. Sustain. Energy 2018, 37, 155-164. [CrossRef]

7. Long, J.W.; Bélanger, D.; Brousse, T.; Sugimoto, W.; Sassin, M.B.; Crosnier, O. Asymmetric Electrochemical Capacitors-Stretching the Limits of Aqueous Electrolytes; Naval Research Lab.: Washington, DC, USA, 2011.

8. Shao, Y.; El-Kady, M.F.; Sun, J.; Li, Y.; Zhang, Q.; Zhu, M.; Wang, H.; Dunn, B.; Kaner, R.B. Design and Mechanisms of Asymmetric Supercapacitors. Chem. Rev. 2018, 118, 9233-9280. [CrossRef]

9. Rahmanifar, M.S.; Hemmati, M.; Noori, A.; El-Kady, M.F.; Mousavi, M.F.; Kaner, R.B. Asymmetric supercapacitors: An alternative to activated carbon negative electrodes based on earth abundant elements. Mater. Today Energy 2019, 12, 26-36. [CrossRef]

10. Volkov, A.V.; Sun, H.; Kroon, R.; Ruoko, T.P.; Che, C.; Edberg, J.; Müller, C.; Fabiano, S.; Crispin, X. Asymmetric Aqueous Supercapacitor Based on p- and n-Type Conducting Polymers. ACS Appl. Energy Mater. 2019, 2, 5350-5355. [CrossRef]

11. Shang, W.; Tan, Y.; Kong, L.B.; Ran, F. Fundamental Triangular Interaction of Electron Trajectory Deviation and P-N Junction to Promote Redox Reactions for the High-Energy Density Electrode. ACS Appl. Mater. Interfaces 2020, 12, 29404-29413. [CrossRef]

12. Carbone, M.; Missori, M.; Micheli, L.; Tagliatesta, P.; Bauer, E.M. NiO Pseudocapacitance and Optical Properties: Does The Shape Win? Materials 2020, 13, 1417. [CrossRef]

13. Wan, C.; Yuan, L.; Shen, H. Effects of Electrode Mass-loading on the Electrochemical Properties of Porous $\mathrm{MnO}_{2}$ for Electrochemical Supercapacitor. Int. J. Electrochem. Sci. 2014, 9, 1.

14. Li, Y.; Xu, X.; He, Y.; Jiang, Y.; Lin, K. Nitrogen Doped Macroporous Carbon as Electrode Materials for High Capacity of Supercapacitor. Polymers 2017, 9, 2. [CrossRef] [PubMed]

15. Sauvage, F.; Chhor, S.; Marchioro, A.; Moser, J.E.; Graetzel, M. Butyronitrile-Based Electrolyte for Dye-Sensitized Solar Cells. J. Am. Chem. Soc. 2011, 133, 13103-13109. [CrossRef] [PubMed]

16. Wu, J.; Lan, Z.; Lin, J.; Huang, M.; Huang, Y.; Fan, L.; Luo, G. Electrolytes in Dye-Sensitized Solar Cells. Chem. Rev. 2015, 115, 2136-2173. [CrossRef]

17. Sengottaiyan, C.; Jayavel, R.; Shrestha, R.G.; Subramani, T.; Maji, S.; Kim, J.H.; Hill, J.P.; Ariga, K.; Shrestha, L.K. Indium Oxide/Carbon Nanotube/Reduced Graphene Oxide Ternary Nanocomposite with Enhanced Electrochemical Supercapacitance. Bull. Chem. Soc. Jpn. 2019, 92, 521-528. [CrossRef]

18. Zhu, F.; Liu, W.; Liu, Y.; Shi, W. Construction of porous interface on CNT@NiCo-LDH core-shell nanotube for supercapacitor applications. Chem. Eng. J. 2020, 383, 123150. [CrossRef] 
19. Wei, H.; Wang, H.; Li, A.; Li, H.; Cui, D.; Dong, M.; Lin, J.; Fan, J.; Zhang, J.; Hou, H.; et al. Advanced porous hierarchical activated carbon derived from agricultural wastes towards high performance supercapacitors. J. Alloy. Compunds 2020, 820, 153111. [CrossRef]

20. O'Connell, M.J.; Boul, P.; Ericson, L.M.; Huffman, C.; Wang, Y.; Haroz, E.; Kuper, C.; Tour, J.; Ausman, K.D.; Smalley, R.E. Reversible water solubilization of single wall carbon-nanotubes by polymer wrapping. Chem. Phys. Lett. 2001, $342,265$. [CrossRef]

21. Shim, M.; Javey, A.; Kam, N.W.S.; Dai, H. Polymer Functionalization for Air-Stable n-Type Carbon Nanotube Field-Effect Transistors. J. Am. Chem. Soc. 2001, 123, 11512. [CrossRef]

22. Reddy, A.L.M.; Shaijumon, M.M.; Gowda, S.R.; Ajayan, P.M. Multisegmented Au-MnO $2 /$ Carbon Nanotube Hybrid Coaxial Arrays for High-Power Supercapacitor Applications. J. Phys. Chem. 2009, 114, 658. [CrossRef]

23. Kaempgen, M.; Chan, C.K.; Ma, J.; Cui, Y.; Gruner, G. Printable thin film supercapacitors using single-walled carbon nanotubes. Nano Lett. 2009, 9, 1872-1876. [CrossRef] [PubMed]

24. Chowdhury, T.S.; Grebel, H. Supercapacitors with electrical gates. Electrochim. Acta 2019, 307, 459-464. [CrossRef]

25. Chowdhury, T.S.; Grebel, H. Ion-Liquid Based Supercapacitors with Inner Gate Diode-Like Separators. ChemEngineering 2019, 3, 39. [CrossRef]

26. Balducci, A.; Dugas, R.; Taberna, P.L.; Simon, P.; Plee, D.; Mastragostino, M.; Passerini, S. High temperature carbon-carbon supercapacitor using ionic liquid as electrolyte. J. Power Sources 2007, 165, 922-927. [CrossRef]

27. Ruiz, V.; Huynh, T.; Sivakkumar, S.R.; Pandolfo, A.G. Ionic liquid-solvent mixtures as supercapacitor electrolytes for extreme temperature operation. RSC Adv. 2012, 2, 5591-5598. [CrossRef]

28. Tsay, K.C.; Zhang, L.; Zhang, J. Effects of electrode layer composition/thickness and electrolyte concentration on both specific capacitance and energy density of supercapacitor. Electrochim. Acta 2012, 60, 428-436. [CrossRef] 